\title{
CRISIS AGRARIAS EN LA ASTURIAS DEL SIGLO XVII. UNA APROXIMACIÓN A SU ESTUDIO
}

\author{
Juan DíAz Álvarez \\ Universidad de Oviedo
}

\section{Resumen}

EI cereal fue el alimento básico que permitió subsistir a la sociedad del Antiguo Régimen, por lo que su abasto fue una de las principales tareas, tanto del gobierno central, como una preocupación constante de los gobiernos locales, y en última instancia de las oligarquías municipales.

En este breve estudio, nos centramos en las principales crisis agrarias acaecidas en la Asturias del siglo XVIl y, más concretamente, en las que afectaron más de cerca a la capital del Principado, Oviedo. Tras un siglo XVI plagado de problemas de abastecimiento, dada la poca productividad de los cereales tradicionales en la región, el siglo XVII parece dar un respiro al cabildo municipal. A pesar de ello, la geografía específica asturiana, y las cíclicas climatologías desfavorables -periodos de gran humedad seguidos de sequias- perjudicó en no pocas ocasiones al territorio ástur.

Palabras clave: Crisis agrarias, abasto de cereal, Asturias, Oviedo, siglo XVII.

\begin{abstract}
The supply of bread was very important for the survival of people of the Ancien Regimen. It involved, for municipal politcans of that age, a great effort to prevent that the agrarian crisises could lead to demographical crisises, which could reduce the number of people in the city, and it would cause social disturbances.

In this article, we make an outline of the most important agrarian crisises (that there were in Asturias) in the $17^{\text {th }}$ century, although we centre on the city of Oviedo. These crisises were mainly bad weather, which ocasionaly was very rainy or very dry, so that municipal politicans had to buy cereals outside Asturias to provide bread to the city. In spite of, some years were good and there was not shortage of cereals in the Asturias at that time which could sell outside.
\end{abstract}

Key words: Agrarian crisises, provisioning of bread, Asturias, Oviedo, $17^{\text {th }}$ century. 
E1 estudio de las crisis de subsistencia y sus consecuencias de carácter epidémico en las sociedades del Antiguo Régimen han constituido elementos de trabajo fundamentales para conocer la demografia, la economía y aspectos varios de la historia social de la época.

En este breve artículo tan sólo pretendemos esbozar las principales crisis agrarias acaecidas en Asturias a lo largo de la décimo séptima centuria. Lo peculiar de la geografia, el clima y la organización del espacio agrario ástures, condicionó su producción cerealística. El Principado no se destacó por este tipo de producción agraria, sus cosechas le permitieron vivir el día a día, sin esperar grandes excedentes. A pesar de todo, las crisis agrarias que citaremos se caracterizaron por su localismo. Nos centraremos de modo preferente en las que afectaron a la zona central de la región y su incidencia en la capital del Principado, Oviedo. Otro de los aspectos que se pretenden apuntar es el esfuerzo por parte de la oligarquía municipal ovetense por la supervivencia de su población a través de actuaciones varias. En la necesidad de panificación del cereal tuvo su importancia diversos sectores: molineros, horneros y panaderas. Nosotros nos centraremos en el protagonismo del horno como un instrumento más al servicio del abasto del pan en la ciudad.

Las fuentes básicas con las que hemos trabajado se restringen a los Libros de acuerdos municipales de la ciudad de Oviedo, complementados con los Libros de arriendos de propios de la ciudad, sobre todo en relación a los hornos que dependían del gobierno municipal; también hemos contado con los Libros de actas e Índices de materias de la Junta General del Principado de Asturias. Además se han utilizado interesantes repertorios documentales que nos han facilitado la labor investigadora'. Por otro lado, la bibliografía sobre la economía asturiana y, en especial sobre crisis de subsistencia y abasto de pan es escasa; es un campo poco trabajado, en el que encontramos esporádicas contribuciones que nos puedan ayudar ${ }^{2}$. Junto a los estudios de tipo

\footnotetext{
1. Actas de las Juntas y Diputaciones del Principado, 7 vols., IDEA, Oviedo, 1949-1964. VILLA GONZALEZRí, M." P.: Catálogo-Inventario del Archivo Municipal de la Cindad de Oviedo, 3 tomos en 5 vols., Oviedo, 1987. Coronas GonzÁlez, S. M. (dir.): Fueros y Ordenanzas. I. Oviedo, 2 vols., Junta General del Principado de Asturias, Oviedo, 2004.

2. En este sentido, junto a las Historias de Asturias editadas por Ayalga, 1977, Silverio Cañada, 1978 y Prensa Asturiana, 1990, cabe citar las obras de BouzA, F.: «Introducción del cultivo del maíz en Asturias en el siglo XVII», en BIDEA, 16, 1952; BARREIRO MALLÓN, B.: «La introducción de nuevos cultivos y la evolución de la ganadería en Asturias durante la Edad Moderna», en Actas del Congreso de Historia Rural, Madrid, 1984; «Producto agrario y evolución de la población en Asturias, siglos XVI-XIX», en BIDEA, 133, 1990; «Los montes comunales y la coyuntura socio-económica en el Occidente de Asturias en los siglos XVI a XVIII》, en Homenaje a Juan Uria Riu, vol. I, Oviedo, 1997; ANES, G.: Economía y sociedad en la Asturias del Antiguo Régimen, Barcelona, 1988; OCAMPo SuÁREZ-VAldÉs, J.: Campesinos y artesanos en la Asturias preindustrial, 1750-1850, Gijón, 1989; GARCIA FERNÁNDEZ, J.: Sociedad y organización tradicional del espacio agrario en Asturias, Gijón, 1989; LÓPEZ, R. J.: «Epidemias y crisis de subsistencia en Asturias durante el Antiguo Régimen», en Hispania, 172, 1989; MENÉNDEZ. GonZÁlEZ, A.: Elite y poder: la Junta General del Principado de Asturias, 1594-1808, Oviedo, 1992; FerNÁNDEZ ÁLvAREZ, J. M.: Subsistencia y supervivencia en la ciudad de Oviedo y su concejo en el siglo XVI, Tesis Doctoral inédita, Universidad de Oviedo, 2001; Peste y supervivencia en Oviedo (1598-1599), Oviedo, 2003.
} 
regional contamos con contribuciones de tipo general y colectivas, que nos adentran en la realidad de otros espacios de la Monarquía Hispánica3 ${ }^{3}$.

\section{EL CEREAL. CULTIVO TRADICIONAL}

La agricultura asturiana estuvo determinada por el espacio geográfico ampliamente accidentado, la composición de los suelos -amplios espacios calizos en el oriente y silíceos en el occidente-, la climatología húmeda que caracterizó, en todo momento, al Principado durante el Antiguo Régimen; y la organización tradicional del espacio, que se caracterizó por su rigidez, cuyo objetivo fue responder a la autarquía de la familia campesina y al pago de las rentas.

El cultivo del cereal fue determinante en este periodo histórico, lo que revela el hecho del desarrollo de una agricultura tradicional. Esta realidad determinó que el principal valor económico durante el Antiguo Régimen estuviera determinado por la posesión de bienes raíces, principalmente en manos de la nobleza y de la Iglesia, quienes los cedieron en sistemas de arrendamiento y/o de foro al campesinado.

En Asturias los cultivos tradicionales de cereal, desde la Edad Media hasta el siglo XVII, se restringían a la escanda, el centeno, el panizo y el mijo; el trigo se cultivó en determinadas zonas geográficas costeras del occidente y centro de la región. No obstante, escanda y trigo gozaron de gran estima comercial y fue, además, el producto elegido por los propietarios de la tierra para cobrar sus rentas. Si bien es cierto que el panizo y el mijo fueron los cereales utilizados por los grupos sociales más desfavorecidos para su mantenimiento, no menos cierto fue el intento del ayuntamiento ovetense por abastecer a su población con los dos tipos de cereal más estimados por la sociedad.

Dada la importancia del cereal, tanto económica, como alimenticiamente, la organización del espacio agrario asturiano respondió a una racionalización y normativas estrictas que regularon el terrazgo, dedicado con prioridad a los cereales panificables. Así, la organización básica del suelo cerealista asturiano estuvo centrado entorno a la hería, en la que, tras el alza de la cosecha, se introducía al ganado para que pastara los rastrojos. Se trató de un espacio abierto, sin mas divisiones internas que los mojones que diferencian las lindes de las parcelas de los diferentes renteros y foreros; en última

3. Entre otros vid. ANES, G.: Las crisis agrarias en la España moderna, Madrid, 1970; PALOP, J. M.: Hambre y lucha antifeudal. Las crisis de subsistencia en Valencia (Siglo XVIII), Madrid, 1977; CASTRO, C. de: El pan de Madrid. El abasto de las ciudades españolas del Antiguo Régimen, Madrid, 1987; BERNARDO ARES, J. M. de; GONZÁlez BELTRÁN, J. M. (eds.); La administración municipal en la Edad Moderna, Universidad de Cádiz, 1999; ARANDA Pérez, E. J. (coord.): El mundo rural de la España moderna, Universidad de Castilla La Mancha, Cuenca, 2004.

4. García Fernández, J.: Sociedad y organización tradicional..., p. 41.

5. OCAMPo SuÁrez-VAldÉs, J.: Campesinos y artesanos..., pp. 21 y ss. DIAz ÁlVAREZ, J.: «Aproximación al patrimonio rústico de Sebastián Vigil de Quiñones», en ARANDA PÉREZ, F. J. (coord.): El mundo rural..., p. 446. 
instancia, fue una organización sujeta a servidumbres colectivas aunque de aprovechamientos individuales ${ }^{6}$.

El sistema tradicional de siembra implicó un modo de cultivo extensivo, donde el crecimiento productivo se debía tan sólo a las continuas roturaciones para el cultivo, perjudicando el aprovechamiento ganadero. Estos hechos, la nula inversión en el mejoramiento de las técnicas agrícolas, la falta de abonos, se juntaron a veces con los problemas climatológicos, siendo los causantes de las continuas crisis de subsistencia acaecidas en esta región?.

Esta situación se suavizó con la introducción de un nuevo cultivo en el Principado, el maíz. La generalización de este cereal supuso la adopción de un sistema intensivo en la agricultura. Su introducción dentro del sistema agrario asturiano se debió a don Gonzalo de Cancio Donlebún, realizándose las primeras cosechas en los albores del siglo XVil en el occidente de la región. Cultivo de difusión rápida, el maiz pudo paliar las necesidades de los grupos sociales más humildes al adaptarse de forma favorable a la climatología y al ser su rendimiento superior con respecto al trigo y a la escanda. EI nuevo cultivo permitió la disminución de los barbechos en las tierras de mayor calidad, así como la rotación con los cultivos tradicionales ${ }^{8}$.

\section{CRISIS AGRARIAS EN EL SIGLO XVII}

El abasto de pan fue básico para el mantenimiento de las sociedades del Antiguo Régimen. Este hecho implicó un enorme esfuerzo por parte de los órganos políticos rectores de la época, desde el nivel superior, la Corona, al nivel más bajo, el municipio, para impedir que las crisis agrarias desembocaran en crisis epidémicas que mermaran a la población y en conflictos sociales.

A lo largo del siglo XVI los procesos de crisis agrarias se sucedieron. En 1503 se documentó cómo la peste llegó a los concejos de Pravia, Salas, Valdés y Tineo; y, a pesar de los muchos esfuerzos que hizo la capital del Principado-como pudo ser la prohibición del tránsito de gentes-, la epidemia llegó dos años después. Asimismo, hacia 1530 la documentación capitular catedralicia habla de otro brote pestilente".

6. Garcia Fernandez, J.: Sociedad y organización tradicional..., pp. 93 y ss. Fernandez CONDE, F. J.: El señorio del Cabildo ovetense. Estricturas agrarias de Asturias en el tardo medievo, Oviedo, 1993, p. 112.

7. Cuartas Rivero, M.: Oviedo y el Principado de Asturias al final de la Edad Media, Oviedo, 1983, pp. 146 y ss.; BARREIRO MALLÓN, B.: «La economf́a asturiana en los siglos XV! y XVIl», en Historia General de Asturias, tomo 3, Gijón, 1984, p. 33; López, R. J.: «Epidemias y crisis de subsistencia...», pp. 501-523; FERNÁNDEZ ÁlvarEZ, J. M.: Subsistencia y supervivencia...; Peste y supervivencia en Oviedo...

8. BOUZA BREY, F.: «Introducción del cultivo del maiz en Asturias en el siglo XVII», en BIDEA, 16, 1952, pp. 159-173. GÓmEZ-TABANERA, J. M.: «En torno a la introducción del zea mays y su adopción por Asturias y el noroeste hispánico», en BIDEA, 78, 1973, pp. 157-201. BARREIRO MALLÓN, B.: «La introducción de nuevos cultivos...», pp. 299 y s.; GARCIA FERNÁNDEZ, J.: Sociedad y organización tradicional..., pp. 94 y ss.; OCAMPO SuÁrEz-VALDÉs, J.: Campesinos y artesanos..., pp. 26 y ss.

9. CASO, F. de: La construcción de la catedral de Oviedo (1293-1587), Universidad de Oviedo, 1981, pp. 334 y s.; Lóplz. R. J.: «Epidemias y crisis de subsistencia...», pp. 502 y ss.; Vid. también: CORONAS GONZALEz, S. M. (dir.): Fueros y Ordenanzas l..., vol. 1 . 
Pero, sobre todo, se destacaron dos periodos críticos básicos, uno en los años 15731576 y el otro en el periodo finisecular, 1598-1599. El primero de ellos no sólo afectó al Principado, sino que fue un hecho generalizado en todo el reino. El fin de siglo asturiano estuvo marcado por la epidemia pestilente de 1598, que afectó gravemente a la mayor parte del Principado, de modo que las pérdidas demográficas fueron considerables, a lo que hubo que sumar la mala climatología que malogró la cosecha ${ }^{\text {to }}$.

$\mathrm{El}$ inicio del nuevo siglo se vio marcado por la catástrofe antecedente ". La introducción del nuevo cereal, el maíz, y su rápida difusión por la región, permitió minimizar los problemas de déficits alimentarios, si bien es cierto que no resolvió los problemas de subsistencia que acarreaba una agricultura precaria. Por otro lado, se observan varios procesos críticos focalizados; en 1629-1631 en la zona de los valles interiores, en 1647-1650 en los valles y zonas de costa. Problemas climatológicos tuvieron lugar en el centro de la región en 1605, 1628, 1642, 1646, 1648, 1652, 1667, 1685, 1687, 1689,1690 , dado que en Oviedo se solicitó al Cabildo Catedralicio sacase en procesión a la patrona de la Ciudad, Santa Eulalia ${ }^{12}$.

La primera de las crisis agrarias del siglo XVII podemos localizarla en 1605, pues el precio del pan que desde el pósito de la ciudad se servía a las panaderas municipales había subido el $50 \%$ en tres meses y medio ${ }^{13}$. Este extraordinario aumento del coste del pan hizo que el ayuntamiento subvencionara parte del precio, estableciendo el precio del pan para las panaderas, quince días después, en 10 reales la fanega, mientras que el precio del grano en el mercado ovetense se mantenía en los 21 reales $^{14}$. La situación debió de empeorar pues un mes mas tarde el precio para las panaderas sube a los 24 reales, precio que se estipula en los 28 en el mes de octubre ${ }^{15}$. En este mismo mes el ayuntamiento resuelve adquirir grano para la panera municipal, para la provisión de la ciudad y su concejo. Se nombraron comisionados, a los que se les encargó lo compraran en Castilla, éstos no pudieron adquirirlo por lo excesivo de su precio. Ello motivó al ayuntamiento a tener que comprarlo en otros «conçejos deste Prençipado, iglesias y monasterios dél hasta la cantidad de quinientas anegas de pan descanda» a un precio entre los 26 y 28 reales. Este hecho revela de forma clara una crisis puntual en la zona central de la región que afectó de forma considerable a la capital del Principado, pues ante una nueva compra que realiza Oviedo el trigo es adquirido al almirante don Diego

10. LópeZ, R. J.: «Epidemias y crisis de subsistencia...», pp. 502 y ss. Fernández Álvarez, J. M.: Peste y supervivencia...

11. El fantasma de la peste estaba cercano por lo que en la Junta General de 8 de marzo de 1600 se establecieron modos de actuación en los casos de peste, mortalidad ocasionada por la misma y carestía de grano (A.H.P.A., Junta General, Sig. 71: Libro de indice de materias, fol. 432 v.)

12. LÓPEZ, R. J.: «Epidemias y crisis de subsistencia...», pp. 510 y s.

13. El precio de la fanega de pan que se servió a las panaderas en 10 de noviembre de 1604 estaba tasado en 14 reales, en 1 de marzo de 1605 su precio ascendió a los 21. (A.M.O., A-15: Libro de Acuerdos, 16031606, sesión de 10 de noviembre de 1604, ff. 185 v.-186, y de 1 de marzo de 1605, ff. 217 v-218.)

14. Ibídem, sesión de 15 de marzo de 1605 , fol. $221 \mathrm{v}$.

15. lbidem, sesión de 27 de abril de 1605, ff. 232-232 v., sesión de 14 de octubre de 1605, fol. 279. 
de Valdés, vecino de la villa de Gijón, quien disponía de 100 fanegas que vendió a precio de 20 reales cada una ${ }^{16}$. A pesar de todo ello, el precio del pan en el mercado en el año 1606 se mantenía en los 28 reales $^{17}$.

La ciudad no se había recuperado de este desastre cuando a finales de marzo de 1607 el ayuntamiento acordó hacer procesiones y oraciones para remedio de la sequía que se estaba padeciendo: «La çiudad propuso la gran neçesidad que ay de agua por el temporal que corre tan caliente y seco, por cuya causa se pierden todos los granos, y pan, y mas mantenimientos $\rangle^{18}$. Problemas también los hubo en 1609 pues el ayuntamiento acordó adquirir 1.000 fanegas de escanda a precio de 16.5 reales ${ }^{19}$. Mala climatología afectó de nuevo a la ciudad en 1619 pues se hicieron rogativas a Santa Eulalia $^{2 n}$.

En la Diputación de 26 de noviembre de 1643 se solicitó al Gobernador del Principado disponer la traída de «trigo de Francia a este Prinçipado, por quanto en este año ha sido grande la falta de pan y es grande la carestía que de el corre, y dificultosso y caro el traerlo de Castilla, por los grandes portes $\rangle^{21}$. Una nueva solicitud de abastecer con trigo francés se vio dos meses más tarde, en la Junta de 15 de enero de 1644 , solicitando -si fuera necesario- la licencia real correspondiente ${ }^{22}$; la resolución de la misma permitió la traída de 10.000 fanegas de trigo ${ }^{23}$.

Dada la crisis que atravesó la región en el periodo 1647-1650, el Principado se vio obligado a no llevar a cabo una Licencia Real que permitía la saca de 6.000 fanegas de pan para socorrer a la plaza de Ceuta. Las dificultades por las que atravesó la región el año anterior aún se notaban, recomendándose «no se enbarque ni saque deste Prinzipado de aqui a ultimo de julio deste año pan, trigo, maiz, paniço ni mijo ni otro jenero de grano de que se haga pan», pero permitiendo la exportación de castaña, nuez y avellana ${ }^{24}$. La negativa se volvió a repetir en la Junta de 23 de enero de $1648^{25}$. Problemas epidémicos se apuntan en 1649, cuando en la Junta General de 9 de marzo se da noticia de la peste que azotaba a la ciudad de Sevilla. Como medio de protección se prohibió el comercio marítimo con aquella ciudad ${ }^{26}$. Asimismo, Oviedo adoptó diversas medidas contra el posible contagio ${ }^{27}$.

16. Ibídem, sesión de 29 de diciembre de 1605, ff. 294-294 v, y de 11 de enero de 1606, fol. $295 \mathrm{v}$.

17. Ibídem, sesión de 25 de octubre de 1606, fol 355 .

18. A.M.O., A-16: Libro de Acuerdos, 1607-1613, sesión de 27 de marzo de 1607, fol 381.

19. Ibídem, sesión de 5 de noviembre de 1609 , fol. $603 \mathrm{v}$.

20. A.M.O., A-17: Libro de Acuerdos, 1614-1619, sesión de 8 de mayo de 1619, fol. 386.

21. Actas de las Jintas y Diputaciones..., tomo IV, p. 106.

22. Ibídem, pp. 158 y ss., 197 y s. y 203.

23. A.H.P.A., Junta General, Sig. 72: Libro de indices de materias, fol. 282.

24. Actas de las Juntas y Diputaciones..., tomo VI, pp. 125 y s.

25. A.H.P.A., Junta General, Sig. 72, fol. 282 v.

26. Actas de las Juntas y Diputaciones..., tomo VI, pp. 194 y s.

27. A.M.O., A-23: Libro de Acuerdos, 1647-1649, sesión de 22 de mayo de 1649, ff. 486 v.-487. 
1650 fue otro año crítico. La ciudad acordó, en mayo, hacer rogativas a la Virgen del Rosario - a propuesta de la cofradía del mismo nombre- dada la falta de agua para el campo ${ }^{28}$ y más tarde en honor de Santa Eulalia, pues en agosto aún permanecía la sequía $^{29}$. En este mismo mes se tasó el precio de la fanega de escanda en 28 reales y la de maíz en 18 , pues dadas las condiciones climatológicas que se habían padecido se esperaba mala cosecha para el año en curso. Efectivamente, en el mes de octubre la ciudad propuso, de cara a la Junta General que se iba a celebrar, la prohibición de comercializar la castaña tanto en Oviedo como en el Principado, dada la «esterilidad de los frutos deste año convendrá el prohibir la enbarcaçion de la castaña desta çiudad e Prinzipado, mantenimiento comun de los pobres y de mucha inportanzia en esta tierra $\rangle^{30}$.

Nuevas Licencias de la Corona que permitían la saca de grano en periodos críticos se trataron en la Junta de 8 de abril de 1658, en la Diputación de 11 de abril de 1658, en la Junta de 20 de junio de 1661 y en la Diputación del día siguiente; en la Junta de 16 de noviembre de 1661, en las Diputaciones de 5 de abril y de 28 de julio de $1670^{31}$; no llevándose a cabo ninguna de ellas. En la Diputación de 23 de octubre de 1675 se resolvió que «mediante la falta general de granos y que se puede experimentar mayor padecer la misma el Reyno de León, se escriva para prebenirse al señor Capitán de Galicia y señores Gobernadores de La Coruña y Betanzos, que den licencia para sacar granos», en la misma sesión se tasó el precio de la escanda en 46 reales y el del maíz en 33 «a efecto de evitar que con la falta se pretendiese cobrar a mayores precios» $»^{32}$. En la Diputación de 18 de febrero de 1678 se recibió la petición de la saca de grano para la provisión de Fuenterrabía, pero se escribe denegándola por la escasez del Principado, en cambio se otorgan 2.000 fanegas para Vizcaya en la Diputación de 6 de junio ${ }^{33}$.

Nueva necesidad de cereal tuvo Oviedo en 1675, pues el ayuntamiento mandó librar a Martín de Cariaga 10.000 reales para la compra de trigo en la ciudad de León ${ }^{34}$, dada la falta de frutos que había en Oviedo y su consecuente alza de precios. La inversión total que tuvo que afrontar la ciudad ascendió a 14.730 reales, pues hubo que sumar los gastos de los portes por el transporte ${ }^{35}$. A este gasto se añadió el que supuso las rogativas a Santa Eulalia para remedio del mal tiempo, que ascendió a 1.154,5 reales ${ }^{36}$.

28. A.M.O., A-24: Libro de Acuerdos, 1650-1652, sesión de 11 de mayo de 1650, ff. 37 v.-38 v.

29. Ibídem, sesión de 3 de agosto de 1650 , fol. 103 .

30. Ibídem, sesión de 14 de octubre de 1650, fol. 153.

31. Actas de las Juntas y Diputaciones..., tomo VII, pp. 71 y s., $80,95,97$ y 192 y s.

32. A.H.P.A., Junta General, Sig. 72, fol. 283.

33. Ibídem. MENÉNDEZ GONZÁLEZ, A.: Élite y poder..., pp. 453 y ss.

34. A.M.O., C-C: Libro de la Razón: Primera Parte, 1658-1685, libranza de 12 de mayo de 1675, fol. $139 \mathrm{v}$.

35. Ibídem, libranza de 20 de junio de 1676 , fol. $143 \mathrm{v}$.

36 . Ibídem, libranza de 12 de mayo de 1675 , fol. $139 \mathrm{v}$. 
E1 periodo más crítico se inscribe en las postrimerías del siglo, en 1693-1694; crisis que veremos de forma más específica en el punto siguiente. En 1699 localizamos la última de las crisis agrarias asturianas de la centuria; crisis que parece se inscribió en una general para todo el reino, pues en la Diputación de 23 de mayo se recibió una orden impidiendo la importación de cereal de León y Astorga al representar un «daño que se sigue mediante la escasez que padece todo el País y necesidad de socorrer los vecinos en los mercados»), se intentó entonces con Galicia pero el Capitán General de aquel reino denegó la petición, noticia que se tuvo en las Diputaciones de 11 de septiembre y de 25 de noviembre ${ }^{37}$.

No sólo representaron un problema las crisis agrarias que proporcionaban cosechas cerealísticas insuficientes para el mantenimiento de la población. Por el contrario, los años de abundancia también constituían un problema; el precio del grano bajaba drásticamente y los órganos gubernativos locales y regionales, así como los particulares, no sabían cómo deshacerse del excedente que atesoraban, pues corría el riesgo de perderse, ya que la harina no aguantaba más de dos años almacenado. En estos casos se demandó a la Junta General el permiso para poder exportar el grano sobrante y poder obtener beneficio económico con ello.

A pesar de las continuas crisis que se padecieron a lo largo del siglo XVI contamos con noticias de exportación de excedente cerealístico ${ }^{38}$ en aquella centuria. Con respecto al siglo XVII, en la Junta General de 3 de junio de 1626 se informó al Corregidor de que «en los puertos de Jijon esta cargado para fuera del cantidad de pan escanda y ottras simillas, con color de que este Principado, por la missericordia de Dios, ay mucha abundancia» ${ }^{39}$, se volvió a dar noticia de la buena cosecha -solicitando la saca de grano- en la sesión de 4 de junio, pues todo parecía indicar muy buenas perspectivas para la siguiente ${ }^{40}$.

Una nueva petición de saca de cereal se demandó una década más tarde. En la Junta de 14 de marzo de 1636 se solicitó al Gobernador «se sirba de dar liçencia para que se saque pan y mayz para probeer las probincias comarcanas que padeçen necesidad y donde tiene preçio y balor; y que por aber mucha abundançia en este Prenzipado, no le tiene, y que se pierde y pudre ${ }^{41}$. Así, en la Junta de 22 de marzo se pidió se dieran poderes a don Diego Bernaldo de Quirós, Procurador General del Principado, para que en la Corte solicite el permiso regio para tal operación ${ }^{42}$.

37. A.H.P.A., Junta General, Sig. 72, fol. 283 v. MEnÉndeZ GonzÁlez, A.: Elite y poder..., p. 454.

38. URIA RIU, J.: El aprovisionamiento de cereales en la Ciudad y otros lugares de la provincia en el siglo XVI. Notas para la historia de Oviedo, Oviedo, 1970. Cuartas Rivero, M.: Oviedo y el Principado de Asturias..., pp. 343 y ss.

39. Actas de las Juntas y Diputaciones..., tomo III, p. 66.

40. Ibídem, pp. 71 y s.

41. Ibidem, p. 282.

42. Ibídem, p. 288. 


\section{CRISIS FINISECULAR DE 1693-1694}

El periodo más crítico del siglo se concentró en las postrimerías de la centuria. Una crisis interna y generalizada tuvo Jugar en 1693-1694, donde la mortandad más importante del siglo se localizó en el concejo de Gijón ${ }^{43}$. Las inclemencias climatológicas malograron las cosechas. Efectivamente, en mayo de 1693 el licenciado don Gabriel de Noreña Hevia, Juez Ordinario de Oviedo, se hizo eco de las catástrofes climáticas cuando expueso «que a causa de los malos temporales no se pudian senbrar los frutos de maiz y el pan. Con la abundançia de las aguas y malos temporales se atrasava». Para remedio de los males solicitó se pidiera al cabildo catedralicio sacase en procesión a la patrona de la ciudad, Santa Eulalia ${ }^{44}$. Una semana después el gobernador propuso sacar en procesión a la Virgen del Rosario con la finalidad de hacer nuevas rogativas, pues la climatología no mejoraba y era desfavorable en toda la región ${ }^{45}$. Éstas se continuaron. En junio una comisión de la cofradía de la Valesquida pidió al ayuntamiento una limosna que sufragara parte de los gastos que realizaron al sacar a su patrona en procesión ${ }^{46}$.

Así el año 1693 parece ser resultó demasiado lluvioso, hasta el extremo de «que con la abundancia de las aguas se abian ronpido los conductos [de las fuentes] por diferentes partes $\rangle^{47}$. Este clima contrasta con el del año siguiente, en el que el problema fue la sequía. En abril de 1694 se solicitaron rogativas a Santa Eulalia «por falta de agua para la conserbazion de los frutos $\rangle^{48}$, meses más tarde, en la Diputación de 1 de agosto, se dio cuenta de «la mortandad y calamidades que se estaban padeciendo en el Principado con el motibo de la estirilidad $»^{49}$.

Ante tal situación el ayuntamiento se vio obligado a actuar, por lo que resolvió realizar una compra de cereal en Castilla para la provisión de la ciudad. En 15 de abril de 1693 se dio cuenta en el ayuntamiento de la llegada de un cargamento de trigo procedente de Astorga, para el abasto de Oviedo. La ciudad había nombrado comisionados para la adquisición del cereal al marqués de Camposagrado y a don Francisco Antonio de Estrada, que fue el encargado de realizar las transacciones en Astorga donde adquirió 250 cargas de trigo (1.000 fanegas por la medida de San Salvador) a don Juan Moreno, canónigo de la catedral astorgana por el precio de 19.500 reales; así como 100 cargas de centeno a don José de Salas, regidor de la ciudad leonesa, por la cuantía de 4.000 reales $^{50}$.

43. LÓPEZ, R. J.: «Epidemias y crisis de subsistencia...», p. 513.

44. A.M.O., A-42: Libros de Acuerdos, 1692-1693, sesión de 13 de mayo de 1693. fol. 79.

45. Ibídem, sesión de 24 de mayo de 1693 , fol. $90 \mathrm{v}$.

46. Ibidem, sesión de 12 de junio de 1693, fol. $113 \mathrm{~V}$

47. lbídem, scsión de 19 de junio de 1693, fol. 122.

48. A.M.O., A-43: Libros de Acuerdos, 1694-1695, sesión de 28 de abril de 1694, fol. 108.

49. A.H.P.A., Junta General, Sig. 70: Libro de indices de materias, ff. 68-68 v.

50. A.M.O., A-42, sesión de 15 de abril de 1693, ff. 60 v.-61. 
En la Diputación de 26 de agosto de 1693 se trató el caso de precio abusivo de los granos, pues se dio noticia de que muchos de los concejos se resistían a aceptar las valías establecidas por la Junta General, teniendo que arbitrar la institución nuevos pre$\operatorname{cios}^{51}$ de acuerdo a la medida de San Salvador. En última instancia, los precios se vieron alterados por los costes del transporte terrestre, portes que eran sacados a remate por el ayuntamiento, y que por cuestiones varias no eran respetados. Así, el acarreo del trigo procedente de Astorga se remató en la persona de Diego Martínez por la cuantía de 10 reales de vellón la fanega, quien «no havia podido allar arrieros que conduxesen dicho pan por dicho alquiler y por la distancia de mas de ttreintta y seis leguas que ai de la ciudad de Asttorga a estta» sufriendo pérdidas personales que superaban los 1.000 reales por lo que solicitó al ayuntamiento le auxiliara dichas pérdidas ${ }^{52}$.

Las catástrofes climáticas afectaron de forma considerable, no sólo a la cosecha de 1693-1694, sino a todos los aspectos económicos de la capital del principado, acrecentando la escasez de los víveres, y por ende su precio, lo que imposibilitó a un alto porcentaje de la población urbana poder aprovisionarse, dado que «los tiempos avian dado ocassion a que ttodas las cosas se acrezenttassen en mucho mas valor de lo que solian andar» ${ }^{53}$. Por ello no es de extrañar que el número de pobres en la ciudad aumentara, de lo que dio cuenta el Gobernador del Principado ${ }^{54}$. Esta situación produjo la saturación de los hospitales de pobres y peregrinos ovetenses, verdaderas instituciones de beneficencia en la época, a los que se acogieron los miembros de los grupos sociales más desfavorecidos. Estas instituciones hospitalarias dependían de las instituciones eclesiásticas, principalmente el Cabildo catedralicio, a excepción del hospital de San Lázaro de patronato municipal ${ }^{55}$.

El aumento de los enfermos hizo reaccionar al regimiento de la ciudad habilitando para su instalación el patio de comedias, así como la asignación de dinero para mantener a los acogidos: «Propuso el señor don Pedro Velarde como para el socorro de los pobres que estan en el patio de comedias se la avia mandado librar por la ciudad dos mil reales $>{ }^{56}$. El aumento de los necesitados ya se había comprobado con anterioridad, cuando el Procurador General de la ciudad, Manuel González Colloto, se hacía eco de las demandas de los médicos de la ciudad, doctores Antonio de Nanclares y Jacinto de la Concha, de que se les aumentara el sueldo por el exceso de trabajo, dado «el mucho numero de enfermos $\rangle^{57}$.

51. A.H.P.A., Junta General, Sig. 86: Libro de Actas, 1693-1695, sesión de 26 de agosto de 1693, fol 39 v.

52. A.M.O., A-43, sesión de 10 de febrero de 1694 , ff. $37 \mathrm{v}$ y ss.

53. Ibidem, sesión de 10 de febrero de 1694 , fol. $39 \mathrm{v}$.

54. A.M.O., A-42, sesión de junio de 1693.

55. Sobre las instituciones hospitalarias ovetenses vid. CABAL, M.: Hospitales antiguos de Oviedo, IDEA, Oviedo, 1985.

56. A.M.O., A-42, sesión de 10 de junio de 1693, fol. 109.

57. Ibidem, sesión de 20 de mayo de 1693 , ff. 82 y ss. 


\section{EL HORNO. UN ELEMENTO MÁS EN EL PROCESO DEL ABASTO DE PAN}

Como hemos observado, el suministro del alimento básico a la población ovetense fue una de las principales preocupaciones del gobierno municipal de la ciudad. Dado que en el siglo XVI las crisis agrarias eran frecuentes, produciendo la consecuente subida de los precios de todos los abastos, así como hambrunas y crisis epidémicas, el regimiento, por iniciativa de la Corona, al igual que sucede en el resto de las ciudades castellanas, crea un sistema de pósitos municipales; Oviedo no es ajeno a ello. Su finalidad fue la acumulación del grano suficiente que pudiera dar abasto a la sociedad en los periodos críticos a un precio razonable, dado que éste se disparaba. No solamente esto, el grano era entregado a determinadas personas, las panaderas reconocidas por el ayuntamiento, que serían las encargadas de hacer moler el cereal y posteriormente amasarlo para venderlo en la plaza pública de la ciudad al precio estipulado por el regimiento.

Todos estos aspectos los vemos ampliamente regulados a través de los acuerdos municipales ovetenses de la décimo sexta centuria ${ }^{58}$, siglo en el que se reguló ampliamente el abasto del pan en la ciudad, creando ordenanzas todos los años que castigaban procederes poco adecuados en un siglo de continuas carencias. Comparativamente, la centuria posterior es menos rígida, lo que puede interpretarse como una mejora en la producción agraria con la introducción de un nuevo cultivo, el maíz, que revolucionó el sistema tradicional agrario asturiano, como ya hemos expuesto.

Las ordenanzas del siglo XVI afectaron a todos los individuos relacionados de una forma u otra con el abasto cerealístico. Desde la creación y regulación de la panera municipal ${ }^{59}$, o la ordenación del trabajo de $\operatorname{los}$ molineros $^{60}$, hasta el funcionamiento de los hornos que dependían de la ciudad para la cocción del pan. Estos instrumentos básicos de cocina fueron sacados a remate de forma periódica por el regimiento, y dado que dependían de los Propios de la ciudad, fueron dados en arrendamiento al mejor postor, del mismo modo que se arrendaron las alcabalas, las sisas, los millones u otras rentas. Las tasas abusivas que los horneros pedían a las panaderas para hornear el pan fue motivo de conflictos entre ambas partes durante el siglo XVl, influyendo, en última instancia, en el precio del pan cocido en el mercado. Ello fue uno de los motivos por los que el cabildo municipal se vio obligado a prefijar una tasa que pudiera contentar a las partes afectadas ${ }^{61}$, para poder mantener el precio del pan accesible a todos los grupos sociales de la ciudad.

58. CoRonas GonzÁlez, S. M.: Fueros y ordenanzas..., vol. I.

59. Vid. FERNÁNDEZ ÁlVAREZ, J. M.: Subsistencia y supervivencia en la ciudad de Oviedo y su concejo...

60. Los molinos fueron unos de los pocos artefactos industriales en los se invirtió tanto las instituciones públicas, como los individuos de forma privada, dado que se convirtieron en instrumentos esenciales en la panificación del cereal, alimento básico en una economía de tipo autárquico; en este sentido, el pan simbolizó la riqueza y el prestigio, cargado de un fuerte valor social. Este artefacto industrial tuvo una doble naturaleza; por un lado, el molino harinero fue una explotación industrial, por otro lado, constituyó una unidad de explotación agraria.

61. Coronas GonzÁlez, S. M.: Fueros y ordenanzas..., vol. I, pp. 287, 314, 677, 851, 878. 
Asimismo el acondicionamiento de los hornos fue algo básico para el surtido de la ciudad. Con ocasión de la crisis de subsistencia de $1598-1599^{62}$, se produjeron desperfectos en algunos hornos y no había personas que pudieran hacer frente a su remate debido a que «estaban arrendados a personas particulares, los quales con el mal de la peste se an muerto y sus fiadores se an muerto, atento lo qual y que se padeçe grande necesidad por no haver quien adereçe los dichos hornos ni adonde coçer el dicho pan de la republica desta ciudad, acordaron sus merçedes que se busquen personas que de balde adereçen los dichos hornos y cueçan el dicho pan al precio por hanega como es costumbre; y no haviendo persona que los adereçe dandoselos sin renta se los den sin ella y se adereçen a costa de propios desta ciudad ${ }^{63}$.

Por otro lado, los hornos tenían unos costes que habían de ser asumidos por el ayuntamiento, se trata de los continuos reparos, esenciales para el buen funcionamiento. Estos arreglos eran sacados a remate. En primer lugar el ayuntamiento estipulaba las condiciones de las obras que habrían de ser realizadas por el albañil o cantero que rematase la obra, seguidamente se sacaba a pregón público el acondicionamiento para su puja, finalmente se firmaba el contrato de obras con el individuo que hubiera hecho la postura más económica ${ }^{64}$.

El horno fue el lugar físico en el que se cocía el pan que posteriormente abastecía a la ciudad. Oviedo dispuso de tres, el llamado de la Plaza ${ }^{65}$, el de la Puerta Nueva y el de Socastiello. El horno de la Plaza era propiedad de Diego Carreño, regidor de la ciudad, quien lo aforó al ayuntamiento por la renta anual de 300 maravedies y la condición de que se le hornease gratuitamente su pan ${ }^{66}$. Dado que los contratos de foro suponen un arrendamiento a muy largo plazo, la ciudad pleiteó con los Carreño en las postrimerías del siglo XVII por su posesión. En 1702 la Real Chancillería de Valladolid otorga Carta Ejecutoria a favor de la Ciudad en contra del regidor ovetense don Francisco Carreño Estrada, que pedía la restitución de su propiedad ${ }^{67}$. El horno de la Puerta Nueva estuvo localizado junto al Matadero, desapareciendo en 1813 a causa de un incendio; el horno de Socastiello, también llamado de Santiago o de Santa Clara, estaba arrimado a la muralla de la ciudad y a la vivienda de la Casa de Meres ${ }^{68}$.

El contrato de arrendamiento establecía unas normas básicas que se repiten casi íntegramente a lo largo de los siglos de la Edad Moderna. El alquiler de estos establecimientos salía a remate público, y el contrato de arrendamiento con el ayuntamiento

62. Vid. Fernández Álvarez, J. M.: Peste y supervivencia en Oviedo...

63. CORONAS GONZÁlez, S. M.: Fueros y ordenanzas..., vol. I, p. 804.

64. A.M.O., D-17, doc. 2: Escrituras de arriendos y fianzas del horno de la Puerta Nueva, ff. 7-8; A-43, sesión de 4 de enero de 1694 , fol. 6.

65. Estaba localizado en la calle del Carpio hasta 1781 cuando su solar se cedió -debido a un incendio-- al marqués de San Esteban del Mar a cambio de otro frente al horno de la Puerta Nueva. (A.M.O., D-17, doc. 2 , ff 29 y s y $36-38 \mathrm{v}$ )

66. A.M.O., D-17, doc. 1: Escrituras de arriendos y fianzas del horno de la Plaza, ff. 1-2 vto.

67. Ibidem, ff. 16-44.

68. Villa GONZÁlez-Rí, M." P.: Catálogo-Inventario del Archivo..., p. 785. 
se establecía por un espacio de tiempo que oscilaba entre los dos a los cuatro años ${ }^{(1)}$. El arrendador había de facilitar escrituras de obligación, comprometiéndose a llevar a cabo la cocción del pan de las panaderas autorizadas por el municipio, y de fianza, que garantizara el pago de la renta estipulada por el remate a los Propios de la ciudad a través de fiadores ${ }^{70}$. Por otro lado, para asegurar el funcionamiento del horno, los arrendatarios de los mismos debían establecer contratos de obligación con terceras personas, que aseguraran el suministro del combustible necesario ${ }^{71}$. Con ello el ayuntamiento intentaba no perjudicar el abasto y si los arrendatarios incurrieran en esta falta la Justicia de la ciudad podría actuar sobre ellos.

En algunos contratos se especificó el promedio de ganancia que habría de lograr el hornero con su trabajo. Así, en 26 de junio de 1596 se arrienda, la mitad el horno de la Plaza a favor de Pedro de Luces y Juan Almoriz por espacio de dos años, estableciendo una tasa de 12 maravedíes por fanega de pan que se horneara ${ }^{72}$. En 16 de diciembre de 1648 se remata el horno de la Plaza con 100 reales de promedio ${ }^{73}$; en 10 de mayo de 1647 la ciudad intenta el remate de los hornos según conviniese a la ciudad otorgando un promedio de 200 reales $^{74}$. Simón de la Fuente, fornero, confesó haber ganado en la renta «media decima que inportó sesenta yseis reales y medio», la misma ganancia tubo Bernabé Fernández ${ }^{75}$. (Véase Cuadro I)

Los contratos establecían un régimen estricto de tres cocciones diarias -a las diez de la mañana y a las dos y seis de la tarde-, para que el pueblo pudiera acudir a cocer su pan ${ }^{76}$. El arrendatario haria una hornada extraordinaria si en el último proceso de cocción no se hubiera podido cocer todo el pan o si un número de panaderas municipales to demandaran. El hornero debía de controlar que las panaderas no sacaran el pan antes de hora, al ocasionar un perjuicio para los compradores al variar el peso, dado que problemas de este tipo ya se habían detectado en la centuria anterior, por lo que se intentó regular a través de ordenanzas ${ }^{77}$.

Resulta curioso cómo en ciertas ocasiones, el arrendatario que remata el contrato con un determinado horno no es el que lo trabaja, sino que lo traspasa, aparentemente sin ningún beneficio, a terceras personas, estableciendo en estos nuevos contratos las condiciones que el primero había pactado con el ayuntamiento. En 2 de junio de 1640 el horno de la Plaza es arrendado por Pedro Prieto por espacio de dos años y renta anual de 1.500 reales. Éste, cede el horno a su vez a dos individuos a partes iguales, a Andrés

69. A.M.O., D-17, doc. 4: Remates y escrituras de arriendo de los hornos de la ciudad desde el año 1632 al cle 1678 .

70. A.M.O., D-17, does, $1-3$.

71. A.M.O, D-17, doc. 1, ff 3-3 v

72. A.M.O., D-17, doc. 2, ff 1-3 v.

73. A.M.O., D-17, doc. 4 , fol. 22.

74. Ibídem, ff. $31-31 \mathrm{~V}$.

75. A.M.O. A-42, sesión de 14 de junio de 1693 , ff. $116 \mathrm{v}-117 \mathrm{v}$.

76. VILLA GONZALEZ-RÍo, M.' P.; Catálogo-Inventario del Archivo Municipal..., p. 785.

77. Coronas González, S. M.: Fueros y ordenanzas..., vol. I, p. 395. 
Pérez que pone a Bartolomé García Escadajillo como su fiador, debiendo satisfacer 750 reales anuales por espacio de dos años «para que lo lleve y administre y pague la mitad de la renta». La otra mitad la cede a Domingo Rodríguez Regalado, que pone como fiador a Julián Menéndez Pantín, con las mismas obligaciones que en el caso anterior $^{78}$. Para otros ejemplos véase el cuadro siguiente:

\section{Cuadro I:}

Arrendamiento de los hornos de la ciudad

\begin{tabular}{|c|c|c|c|c|}
\hline \multicolumn{5}{|c|}{ HORNO DE LA PLAZA } \\
\hline AÑo & ARRENDATARIO & TIEMPO & PROMEDIO & REMATE \\
\hline \multirow[t]{2}{*}{1596} & Juan de Luces y Juan Almoriz ${ }^{79}$ & 2 años & $\mathrm{s} / \mathrm{d}$ & $\mathrm{s} / \mathrm{d}$ \\
\hline & Andrés Pérez ${ }^{80}$ & 2 años & $\mathrm{s} / \mathrm{d}$ & $\mathrm{s} / \mathrm{d}$ \\
\hline 1632 & Andrés Pérez & 2 años & $\mathrm{s} / \mathrm{d}$ & $1.370 \mathrm{rs}$ \\
\hline 1634 & Domingo Rguez. Regalado & 2 años & $\mathrm{s} / \mathrm{d}$ & $1.600 \mathrm{rs}$ \\
\hline 1640 & Pedro Prieto ${ }^{81}$ & 2 años & $\mathrm{s} / \mathrm{d}$ & $1.500 \mathrm{rs}$ \\
\hline 1642 & Domingo Rguez Regalado & 2 años & $\mathrm{s} / \mathrm{d}$ & $1.232 \mathrm{rs}$ \\
\hline 1648 & $\begin{array}{l}\text { Juan Alonso y Domingo Rguez } \\
\text { Regalado }\end{array}$ & 4 años & $100 \mathrm{rs}$ & $1.100 \mathrm{rs}$ \\
\hline 1690 & Juan de la Fuente ${ }^{82}$ & 4 años & $\mathrm{s} / \mathrm{d}$ & $1.743 \mathrm{rs}$ \\
\hline 1694 & Juan de la Fuente 83 & 4 años & $\mathrm{s} / \mathrm{d}$ & $2.000 \mathrm{rs}$ \\
\hline \multicolumn{5}{|c|}{ HORNO DE LA PUERTA NUEVA } \\
\hline AÑO & ARRENDATARIO & TIEMPO & PROMEDIO & REMATE \\
\hline 1596 & Alonso de Riosa & 2 años & $\mathrm{s} / \mathrm{d}$ & $\mathrm{s} / \mathrm{d}$ \\
\hline 1632 & Juan de Ayer & 2 años & $44 \mathrm{rs}$ & 693 rs \\
\hline 1634 & Bartolomé Garcia Escadajillo & 2 años & $\mathrm{s} / \mathrm{d}$ & $759 \mathrm{rs}$ \\
\hline 1640 & Pedro Suárez Nicieza & & $\mathrm{s} / \mathrm{d}$ & 825 rs \\
\hline 1642 & Andrés Pérez & 2 años & $\mathrm{s} / \mathrm{d}$ & $500 \mathrm{rs}$ \\
\hline 1647 & Juan de Posada & $\mathrm{s} / \mathrm{d}$ & s/d & $118 \mathrm{rs}$ \\
\hline 1649 & Juan González Paredes & $\begin{array}{l}\text { Foro } \\
\text { vitalicio }\end{array}$ & $\mathrm{s} / \mathrm{d}$ & 330 rs \\
\hline
\end{tabular}

78. A.M.O., D-17, doc. 2, ff 6-7 v. VILLA GonZÁlez-Río, M." P.: Catálogo-Inventario del Archivo Municipal..., p. 786.

79. Arriendan la mitad del horno.

80. Arrienda la otra mitad del horno.

81. Traspasa el horno a Andrés Pérez y a Domingo Rodríguez Regalado, cada uno de ellos paga 750 rs al mayordomo de propios y rentas de la ciudad.

82. A.M.O., A-43, sesión de 2 de marzo de 1694 , fol. 71 v.

83. Ibídem, sesión de 4 de junio de 1694, fol. 119. 


\begin{tabular}{|c|c|c|c|c|}
\hline \multicolumn{5}{|c|}{ HORNO DE LA PUERTA NUEVA } \\
\hline AÑO & ARRENDATARIO & TIEMPO & PROMEDIO & REMATE \\
\hline 1650 & Andrés Pérez y Andrés Gonzáez & $\mathrm{s} / \mathrm{d}$ & $s / d$ & $330 \mathrm{rs}$ \\
\hline 1658 & Juan de Ules y Andrés Pérez & 3 años & $\mathrm{s} / \mathrm{d}$ & $550 \mathrm{rs}$ \\
\hline 1669 & Toribio de Caso y Juan de Ules & 2 años & $\mathrm{s} / \mathrm{d}$ & $660 \mathrm{rs}$ \\
\hline 1671 & Toribio de Caso y Juan de Ules & 4 años & $\mathrm{s} / \mathrm{d}$ & $605 \mathrm{rs}$ \\
\hline 1686 & $\begin{array}{l}\text { Juan de Ules, su mujer y Andrés } \\
\text { de la Cabaña }\end{array}$ & 4 años & $\mathrm{s} / \mathrm{d}$ & $\begin{array}{l}1.493 \mathrm{rs}, \\
28 \mathrm{mvs}\end{array}$ \\
\hline 1691 & José de Cabaña ${ }^{84}$ & 3 años & $\mathrm{s} / \mathrm{d}$ & $1.705 \mathrm{rs}$ \\
\hline \multicolumn{5}{|c|}{ HORNO DE SANTIAGO } \\
\hline AÑO & ARRENDATARIO & TIEMPO & PROMEDIO & REMATE \\
\hline 1630 & Juan Alonso ${ }^{85}$ & 2 años & $132 \mathrm{rs}$ & $1.166 \mathrm{rs}$ \\
\hline 1632 & Juan de Ayer ${ }^{86}$ & 2 años & $\mathrm{s} / \mathrm{d}$ & $1.419 \mathrm{rs}$ \\
\hline 1634 & Medero González de Ferreros & $\mathrm{s} / \mathrm{d}$ & $53 \mathrm{rs}$ & $2.233 \mathrm{rs}$ \\
\hline 1640 & Juan Alonso ${ }^{87}$ & 2 años & $\mathrm{s} / \mathrm{d}$ & $1.100 \mathrm{rs}$ \\
\hline 1642 & Alonso de Niebares & 2 años & $\mathrm{s} / \mathrm{d}$ & $1.122 \mathrm{rs}$ \\
\hline 1648 & Diego de Lezama & 4 años & $\mathrm{s} / \mathrm{d}$ & 968 rs \\
\hline 1653 & Juan Glez. Paredes ${ }^{88}$ & 4 años & $\mathrm{s} / \mathrm{d}$ & $660 \mathrm{rs}$ \\
\hline 1688 & Francisco González Cabaña & $\mathrm{s} / \mathrm{d}$ & $\mathrm{s} / \mathrm{d}$ & $\mathrm{s} / \mathrm{d}$ \\
\hline
\end{tabular}

Fuente: A.M.O., D-17, docs. 1-4 Escrituras de remates, arriendos y fianzas de los hornos.

\section{CONCLUSIONES}

El medio natural asturiano no hizo de la región un espacio cerealista por excelencia. En lineas generales la agricultura asturiana del Antiguo Régimen se caracterizó por la autarquía; el campo asturiano no generó grandes excedentes que permitieran la comercialización del grano, lo que sucedió en muy contadas ocasiones. Esta situación de precariedad hizo que los caprichos climatológicos -sequías o demasiada lluvia hicieran estragos en las cosechas, viéndose los órganos políticos competentes obligados a la importación de cereal para el abasto de la población. No obstante, estos efectos climatológicos no solieron afectar a toda la región por igual, sino que se trató de crisis muy localizadas. Fuera de este campo se localizaron algunas crisis más generales como la de 1598-1599, cuyos efectos se vieron aún en los albores de la centuria ulterior. Por

84. Ibídem, sesión de 2 de marzo de 1694, fol. 71.

85. Traspasa el horno a Domingo Rodríguez Regalado, hornero y vecino de la ciudad.

86. Traspasa el horno a Domingo Rodríguez Regalado y Juan Alonso.

87. Traspasa el horno a Alonso de Niebares y su mujer.

88. Traspasado. No se especifica a quién. 
lo general, el siglo XVII asturiano puede caracterizarse por una relativa normalidad. Lo que no le priva de las crisis puntuales anteriormente citadas.

El esfuerzo por parte de la oligarquía de una ciudad de la cornisa cantábrica como Oviedo por la supervivencia de su población fue continua. En este empeño se entrelazaron un sinfin de hechos y de sectores, desde el campesinado, que trabaja directamente la tierra, al cabildo municipal y la Junta General que reguló y legisló el reparto del grano. Por otro lado, el cereal necesitó de un proceso de panificación, realizado por los molineros y las panaderas nombradas por el ayuntamiento, para su posterior cocción y puesta en venta. El trabajo de tantos individuos tuvo una misma finalidad, el abasto del producto básico de alimentación, lo que no estuvo privado de pocos enfrentamientos, lo que se observa, sobre todo, en el siglo XVI, remitiendo estos hechos en la centuria posterior, que es en la que nos hemos centrado. Finalmente, las continuas variaciones de los precios de los granos constituyen el mejor indicador que tenemos para observar las fluctuaciones de las cosechas, así como los desequilibrios entre la producción agraria y la población. 